$\frac{\text { PART VI }}{\text { Environment and Waste Management }}$ 



\title{
Potential Application of Solar Energy in Sudan
}

Siddig A. Omer

University of Nottingham, $U K$

\begin{abstract}
Sudan is a vast country with extended remote rural areas, where the limited grid electricity can hardly reach. Biomass remains the main source of energy for most households, and this is under threat as deforestation is expanding rapidly due to frequent droughts and high fuel wood consumption rate. Hydropower is currently the main source for electricity supply ( $87 \%$ of Sudan electricity is provided from hydropower) for most of Sudan fragile grid network but, this hardly meets the need of a small proportional of the population. Sudan also enjoys reasonable wind energy resources, with average annual wind speed exceeding $3 \mathrm{~m} / \mathrm{s}$ in many parts of the country. This range of wind speed is well suited to water pumping in some parts of the country, but falls short of the required wind turbines rated wind speed for electricity generation. Currently Sudan is producing considerable amount of oil, which meets part of its energy needs, however, most of this is exported as a main Government income, beside agricultural products. At the same time Sudan enjoys high annual average solar radiation levels throughout the country (approximately $6 \mathrm{kWh} / \mathrm{m} 2 /$ day). This if exploited would meet needs of most of the population, particularly in the rural area where grid electricity is not readily available. This paper outlines some of the potential applications that could be powered using solar energy in the Sudan, and explores the status of some of these technologies.
\end{abstract}

\section{Introduction}

Sudan is a large country with a varied broad range of energy resources and energy needs. In most rural areas, energy is needed to provide lighting during the night, radio or TV operation as well as cooking. Energy consumption from household to another may vary slightly depending on the location and the number of household members. Water pumping is another important area, mainly because of the poor water supply network.

In a study conducted for UNDP funded Area Development Scheme (ADS) in Northern Kordofan State [Omer, 1993], in order to identify potential solar energy technologies, it was revealed that within the rural households cooking and lighting represent the major energy consuming tasks. Fuel cost for cooking represents about $64 \%$ of the total fuel cost and $11 \%$ of the total household expenditure. In some households, lighting represented up to $36 \%$ of the fuel cost and about $6 \%$ of the total household expenditures. People normally use dry batteries and kerosene for lighting, while fire wood and charcoal are the main source for cooking energy.

Apart from the household energy use, energy is also required in boarding school both for cooking and lightings. In health centres, energy is required to run refrigeration for vaccine and other medicine storage. Energy is also needed for sterilization of injection tools. Currently, in many rural area health centres, this is performed using charcoal as an energy source.

Water pumping is another area where energy is desperately needed in the rural area. In Northern Kordofan for example, the study [Omer, 1993] revealed that, hand pumps are widely spread for water pumping, thanks to UNICEF, and open wells are also widely spread, particularly in areas where hand pumps are not successful. Both these two types of water provision mean utilise the human or animal power for water lifting. The main concern about these means of water provision systems is the time and human efforts consumed due to high pumping heads and low pumping yield. 
In the urban areas the energy demand is also varying considerably depending on the style and type of building and its location. Air cooling whether using ceiling fans or air conditioning systems represents the major energy consumption sector in most households, followed by fridges, lighting and other electronic appliances such as TV, radio etc. Electricity is also needed to pump water to elevated storage tanks, almost in all cities due to low water pressure within the local water network. Figure 1 shows break down of electricity consumption in a typical Khartoum household.

It is worth noting that, in Sudan, about $73 \%$ of the energy is consumed in buildings, of this percentage, domestic housing accounts for about $68 \%$ and the rest is consumed in commercial buildings (offices, educational .etc.) [Yasin, 2008]. Transportation also consumes a considerable amount of fuel, especially with the increasing number of cars on the street as a result of the new investment imports polices. However, with the current rate of Sudan oil production this imposes little problem to the energy situation in Sudan.

Fig. 1 Breakdown of energy consumption in typical Khartoum household [Yasin, 2008]

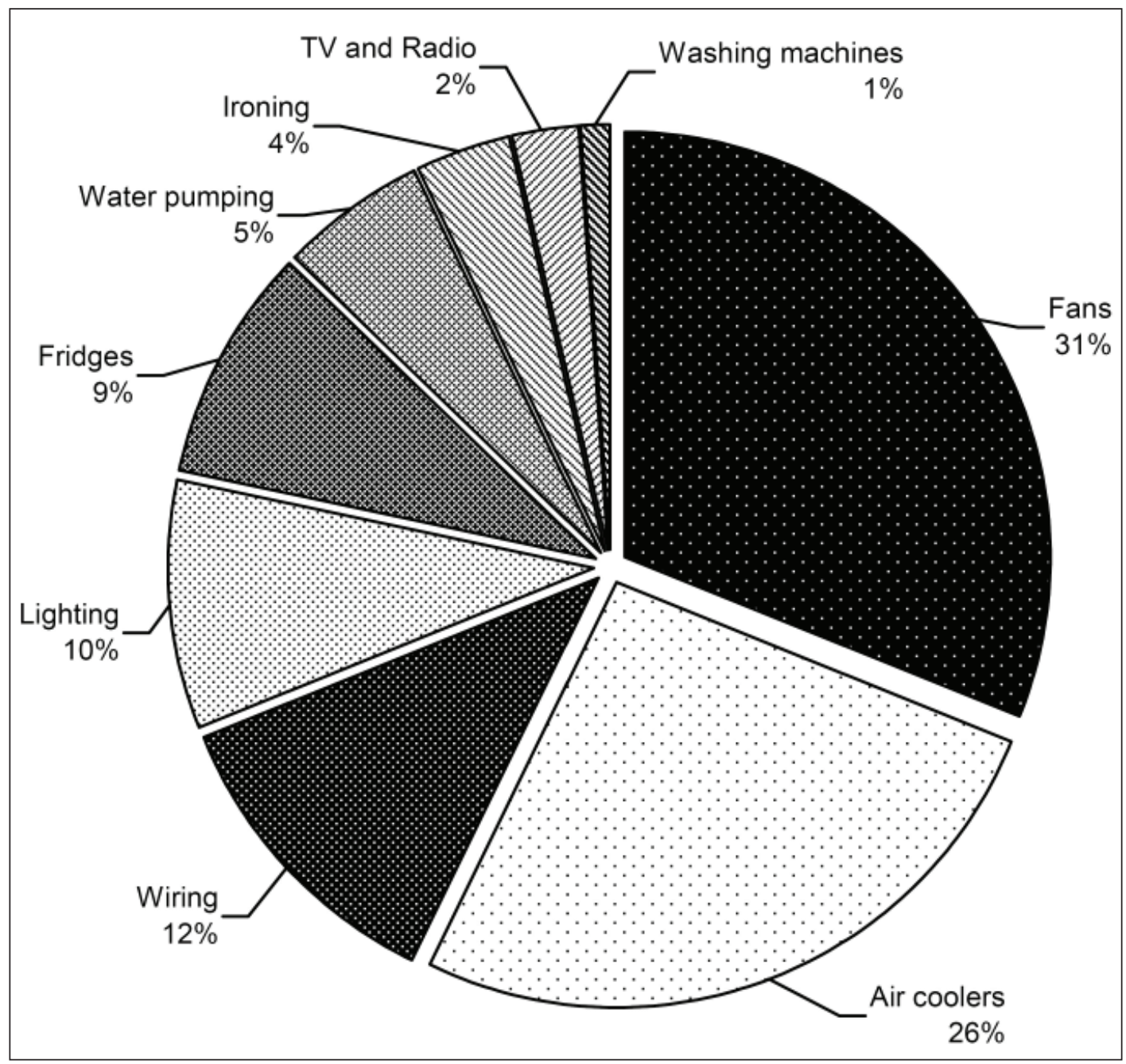




\section{Solar Energy Resources in Sudan}

Solar radiation level in Sudan is very high and seasonally fairly uniform, particularly in the northern part of the country (Figure 2). There are more than 16 meteorological stations that record solar radiation, and records of 10 of these show annual average solar radiation records of at least $6.0 \mathrm{kWh} / \mathrm{m}^{2} /$ day on a horizontal surface [Omer, 1999]. The potential of solar energy in the south is slightly less than that of the north, mainly because of the long rainy season. However, it is still very high compared to many other places in the World, where solar energy is highly utilised.

Fig. 2 Variation of the annual solar radiation on horizontal plane in Sudan [0mer, 1999]

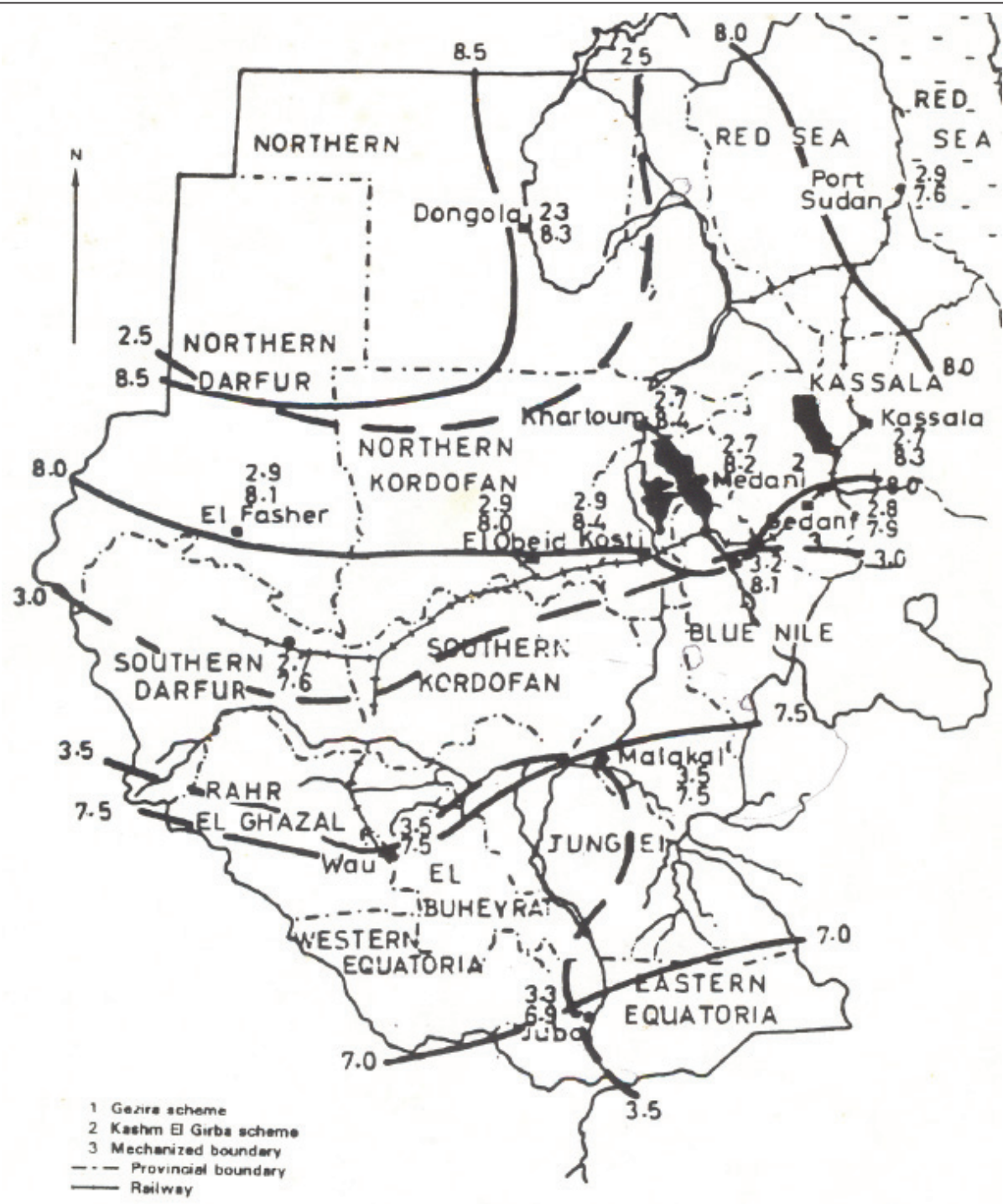




\section{Solar Energy Applications}

Although, there were some attempts through the Energy Research Council of Sudan, to utilise solar energy in Sudan during the 1980s, there are very little efforts being made to use these considerable amount of energy source for beneficial purpose in a wider scale. There are many applications for solar energy, and the major applications and end uses of could be categorised according to the energy form used, whether thermal energy in terms of heat or electrical energy. Taking into consideration energy situation in most of the rural areas, and the state of the art of the solar energy technologies, the following solar applications could be identified as potential solar energy applications in Sudan.

a) Thermal Solar systems, mainly solar cookers

b) Solar electricity - stand alone or grid connected photovoltaic systems for lighting, refrigerators and rural water pumping applications.

\subsection{Solar cookers}

A solar cooker is one of the simplest devices that can be used to convert solar radiation into useful heat energy and which could be used for cooking purposes. Research work and development in the field of solar cookers has matured and to date various designs of solar cookers were introduced in Sudan by Energy Research Institute and some other non-governmental organisations.

Solar cookers that have been developed include direct focusing solar cookers, which are suitable for large scale cooking appliances such as school and other community based activities. These use parabolic dish reflector to focus the direct sunlight onto a dark cooking pot which could be suspended or set on a stand at the focal point of the dish. The most sophisticated part of this device is the parabolic reflector which requires highly skilled labour for its fabrication to produce an accurate reflecting and focusing surface. Various types of materials lined with reflective films could be used to produce efficient concentration. The reflector size can be selected according to the amount of energy required. Consequently direct-focusing solar cookers can be of small size to meet cooking requirements of a small household or of a large size to serve communities such as refugees' camps, boarding school, etc.

A typical direct focusing solar cooker designs include what is known as "FALCO" solar cooker of $1.5 \mathrm{~m}$ diameter reflector which was developed by the Energy Research Council in mid 1980s, and has achieved efficiency up to $25 \%$. The cooker is able to cook $0.5 \mathrm{~kg}$ of rice in 1-litre of water just in half an hour period and $1.25 \mathrm{~kg}$ of meet with $0.5 \mathrm{~kg}$ of onion and 2 litres of water in 2 hours time. The cooker is also able to cook $1.5 \mathrm{~kg}$ of beans (foul) in 1.6 litre of water in 2.5 hours [Omer, 1993].

Another large size community based direct focusing solar cooker was developed and manufactured by Dr Salih Hamadto workshop in Khartoum [Omer, 1993]. This has ability to cook large quantities of food with capacity up to 70 litres. Numerous arrangements have been provided to this cooker, so that the cooking can take place inside the kitchen. An optional conventional fire place is available as a backup system which could be used during non-sunny periods.

Other solar cookers include the simple box type solar cookers, and are suitable for family size cooking applications. This is basically a well insulated closed shallow box with a glass cover. The exposure bottom surface of the box is painted black to absorb solar radiation. The box is provided with a reflective lid which is adjusted to reflect further radiation into the box. The box itself 
can be made of wood, ply wood, chip wood, etc, provided with sufficient insulation and then be glued with aluminium foil or sheet or lined with any reflective film on the inner wall surface.

The entire oven/box need to be oriented facing the sun during cooking period. Food is cooked in covered dark pots or pans positioned inside the box and usually raised from the bottom to permit hot air circulation beneath it. One of the attractive features of the solar box cooker is that it can be used all the day by only little movement to follow the sun. They are relative inexpensive and can be made using local materials. These have efficiency in the range $8 \%$ to $13 \%$ depending on the material used. This type of solar cookers can boil up to a litre of water in less than an hour period under Sudan solar radiation conditions.

Use of solar cookers in rural areas is considered practically possible both for household applications and for community based activities including boarding schools, Quranic schools (Khalwas). According to [Omer, 1993], application of solar cookers could save up to $60 \%$ of the rural household energy requirement, and have payback period not exceeding 4 years. On the other hand several benefits can be achieved from application of solar cookers, and these include:

- Firewood and charcoal consumption can be reduced significantly, which will reduce the rate of desertification.

- Reduce the probability and risk of houses catching fire

- Improvement in the health level among women as a result of reducing their subjection to smoke and burning gases.

- Food cooked on solar cooker never burns, and so preserve food quality, taste and nutrition.

- Development of village level industry to produce solar cookers

\subsection{Solar electrical power}

Electricity is another important element in the social and economic development of rural population, and it can be decisive for the supply of food, drinking water, conservation of food, storage of medical supplies, lighting, telecommunication, radio and TV. One of the simplest ways to utilise solar electricity is by converting it using photovoltaic devices which directly converts solar radiation into electricity. Photovoltaic (PV) devices are very simple and do not require much attention during operation and have minimum maintenance requirement. The only requirement is to install the panels so that they face the sun most of the time. The panels can be installed separately on a supporting frame or integrated into the building depending on the building type and structure.

The potential for PV applications are enormous. Theoretically PV systems could cover the whole electricity demand of most people. The cost of modules of the developed cells is continuously coming down, and newer materials are currently under development, particularly the thinfilms, multi-junctions and may lead to lower production costs and high efficiency.

PV module prices vary considerable depending on the type of cell, size of module, quantity of modules purchased and the supplier. Modules in United state and china for example are cheaper than in Europe and the rest of world. Figure 3 shows the average PV module cost trend over the last 7 years period for European and USA retailers. Currently the average cost of PV module is just under $€ 6 /$ watt peak ( $\$ 7.5$ per watt peak), while in the United states is just under $€ 4.4$ per watt peak (\$5.5 per watt peak), [Solarbuzz, 2009]. 
Fig. 3 Photovoltaic module retail prices (Dec 2001 - Jan 2009), [Solarbuzz, 2009]

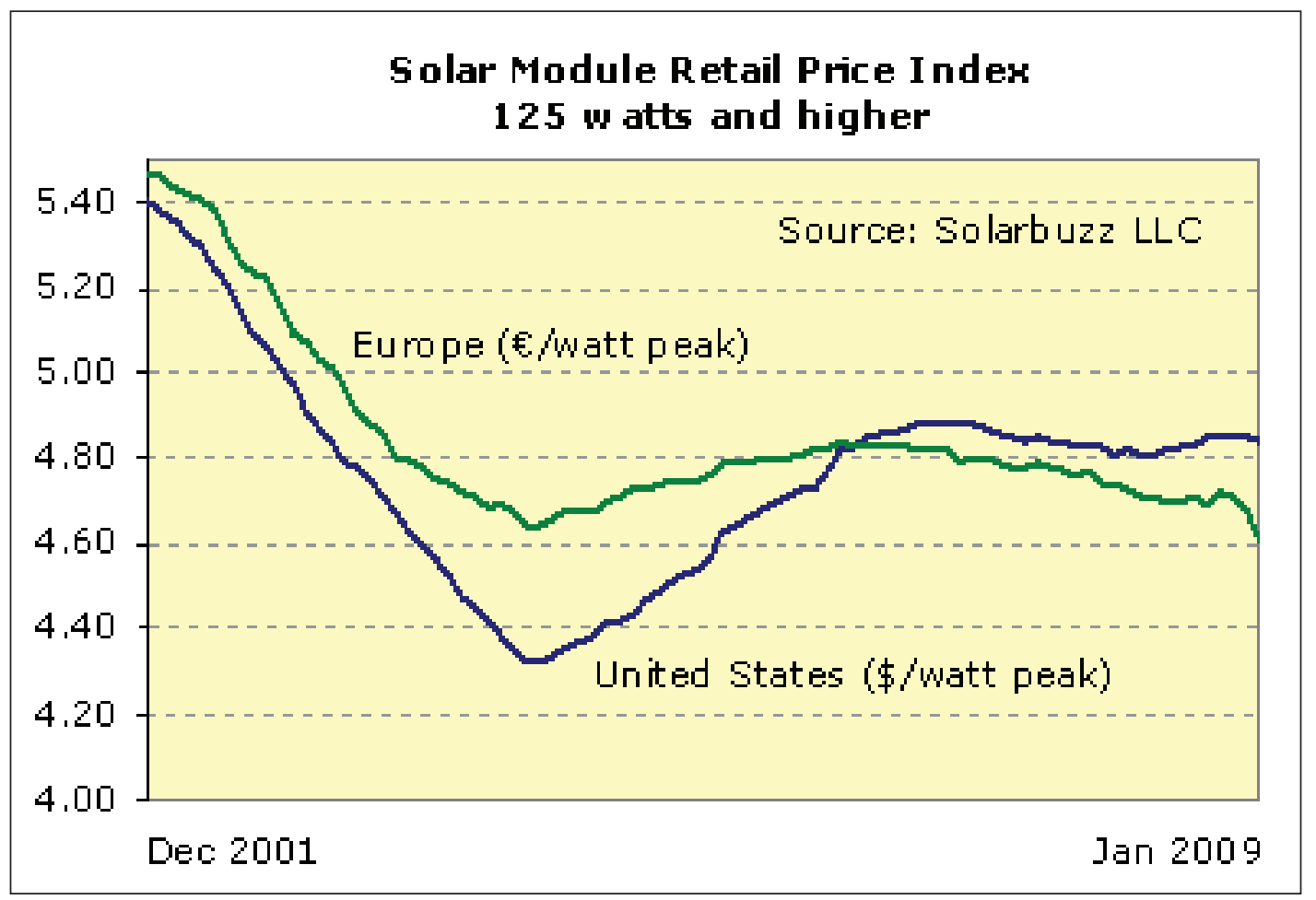

System installation cost varies depending on many factors, including the size and the type of the system. The PV system may be based on a stand alone system, where only very few components are required. The system may be integrated into the building to provide building energy. The system may be connected to the grid to reinforce grid availability. Depending on these, the installation cost will also vary. Table 1 shows the variation of the PV system installation cost based on whether it is grid connected, off grid and the size of the system.

System prices for off-grid applications tend to be higher by about a factor of two than those for grid-connected applications as the latter do not require storage batteries and other associated equipment.

Possible applications of photovoltaic systems can be categorised in to the following major areas:

\subsubsection{Off-grid domestic photovoltaic systems}

These systems provide electricity to remote located households and villages that are not connected to the national electricity grid, and are very much suited to application in rural areas of Sudan.

Table 1 Variation of the installed cots of PV system with size of the plant

\begin{tabular}{|l|c|c|c|c|}
\hline Installation type & \multicolumn{2}{|c|}{ Off-grid } & \multicolumn{2}{c|}{ On-Grid } \\
\hline Size range & $<1 \mathrm{kWp}$ & $>1 \mathrm{kWp}$ & $<10 \mathrm{kWp}>$ & $>10 \mathrm{kWp}$ \\
\hline Cost $(\$ / \mathrm{kWp})$ & $9-25$ & $8-24$ & $5-12$ & $4-10$ \\
\hline
\end{tabular}


Theses PV systems can be used to provide electricity for homes and schools lighting, refrigeration and other low power loads, e.g., TV, radio etc. Thousands of these types of PV systems have been installed worldwide and they are often the most appropriate technologies to meet the energy demands of off-grid communities. Off-grid domestic systems are typically around $2 \mathrm{~kW}$ in size and generally offer an economic alternative to extending the electricity distribution grid at longer distances from existing power lines. The low voltage, direct current modules have limited application and are suitable for operation only when sun shines, unless provided with storage batteries. Most larger and commercial applications require backup systems and controllers for DC to $\mathrm{AC}$ conversion to match the main supply and suit the appliance. These are known as balance of system (BoS) components, and their cost could amount to $50 \%$ of the system cost.

The off-grid PV systems are most appropriate for remote rural application, and can be based on single household size, multiple systems providing electricity to a number of houses. There is an enormous potential of this type solar electricity system in Sudan.

\subsubsection{Off-grid non-domestic photovoltaic systems}

These systems are the most appropriate applications where small amount of electricity has a high value, so making PV commercially cost competitive with other small generating sources. These systems were the first commercial application for terrestrial PV systems. They provide power at a low maintenance for a wide range of applications, such as telecommunications, water pumping, vaccine refrigeration in health centres and navigational aids. Other applications of this type of solar system may include street lighting in urban areas and highways and sign posts. The size of the system may vary considerably depending on the applications.

\subsubsection{Grid-connected distributed photovoltaic systems}

These photovoltaic systems supply power to buildings or other load that is also connected to the utility grid. These systems are usually integrated into the built environment and supply electricity to residential houses, commercial and industrial buildings. There is no need for battery storage units as these systems are connected directly to national electricity grid, thus the costs of these systems are lower compared to an off-grid installation. However, they require invertors co convert the direct current electricity to an alternative current electricity of the grid. Typical systems are between 1 and $100 \mathrm{~kW}$ in size. One feature of these systems is that, the electricity is fed back into the utility grid when the on-site generation exceeds the demand of the local load, while the load could be powered from the grid during low solar insolation. Properly designed, grid-connected PV systems nicely match the residential load pattern during hot summer days, where the demand for cooling is also high due to increasing solar radiation.

Building integrated PV (BIPV) systems are once which are currently given most attention in most of the developed countries. Any building surface that intercepts the sun is a candidate for PV integration. Many buildings incorporate semi-attached elements in addition to walls and roofs, such as awnings, light shelves, canopies and fences. All of these surfaces can deliver the multiple benefits of BIPV; producing energy while performing other architectural functions. Any assessment of the BIPV potential starts with a determination of the total roof and façade area, which is subsequently corrected for architectural suitability for solar utilisation. The common 
practice is to base the BIPV potential on the ground floor area figures, which are transformed into roof and façade surface.

Although, PV panels could be retrofit to existing buildings, the BIPV potential can be improved considerably when this has been considered at the design stage of the building architect. The integration can take different forms, ranging from rooftop integration to facade cladding system and from high quality façade cladding on prestige apartment buildings to less expensive cladding of a warehouse or industrial buildings (See figure 4).

Over the last two decades there has been increasing activity in the field of building-integrated PV systems. Integration of PV into energy-conscious design building could create a new generation of buildings which not only have low energy requirement but also produce environmentally friendly electricity. PV product manufacture are also responding to the increasing interest in BIPV by developing PV products suitable for architectural integration into buildings. In order to allow architectural expression, PV module of different size, colours and degree of transparency are being developed for incorporation into building roof, wall cladding and curtain waling systems. Other advantages of building-integrated PV systems include:

- $\quad$ reduced structural cost of the PV system

- no additional land area is needed,

- Cost credits of replaced building products with functional PV products

- reduced transmission losses, and efficient use of power at point of generation

- $\quad$ improve building aesthetics

These types of PV systems best suit urban area including high rise building.

\subsubsection{Grid-connected centralized photovoltaic systems}

These systems are installed for two main purposes: as an alternative to conventional centralized power generation, or for strengthening the utility distribution system. These may e installed to stabilise and improve the grid reliability, and may vary significantly. These require large land area to install multiple arrays of PV module to provide multi $\mathrm{kW}$ or MW electricity. Given the enormous land area, the solar radiation in Sudan, the poor national grid system, these types of solar systems also have a considerable potential in Sudan.

\section{Fig. 4 Various configuration of building PV integration forms}

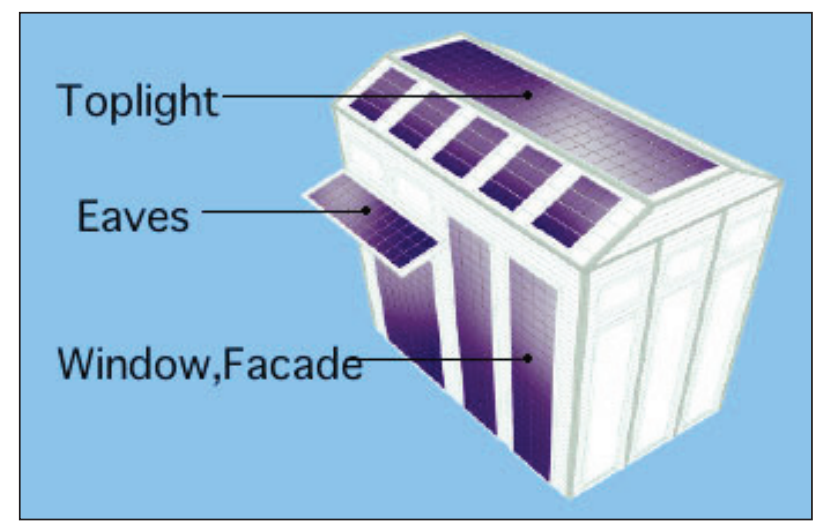




\subsubsection{Water pumping}

Solar water pumping is another area where solar PV electricity could be harnessed to supply water for villagers in the remote areas of Sudan. These involve use of PV modules to produce electricity and use the later to operate water pumps. Application areas may include rural water supply from low head water wells and along the river Nile for irrigation.

There were limited efforts to demonstrate the potential of solar pumps in water pumping in Sudan. According to the report of Sudan Energy Research Council [Hodgkin, 1991], in the late 1970s, the Energy Research Council (ERC) has evaluated the potential of solar-thermal pumping systems. Two Sofretes solar thermal pumps were installed at ERC's Soba Research Station and Hillat Hamedi. These did not prove to be reliable and were abandoned in 1979. The unreliability of the solar-thermal technology and the inadequate technical know-how, in addition to advances in photovoltaic (PV) technology has shifted the focus of research efforts on PV pumps during the 1980s. In the 1978 the United Nations Development Program (UNDP) initiated a solar pumping project, which included the installation and evaluation of the first generation of photovoltaic solar pumping equipment in the country. Two PV pumps were installed at Butri $30 \mathrm{~km}$ south of Khartoum, in 1981. One of these pumps was eventually removed and re-installed at ERC's Soba test site. The results of a series of tests and demonstrations of these pumps indicated a promising potential of PV pumping system under Sudan weather conditions.

In the early 1980s the ERC collaborated with the University of Gezira and the Hodieba Research Centre in the installation of solar pumps in Wad Medani and El Damer. These PV pumps were donated by Grundfos and have been operating without major difficulties. Both pumps were evaluated as part of the ERC/ Sudan Renewable Energy Project (SREP) pumping program. More recently, several solar pumps were provided for evaluation and test by the SEP program. Sudan Especial Energy Programme (SEP) was involved in installation and demonstration of several other PV pumps, including the low head KSB Aquasol floating pumps. One of these was located at Shambat in Khartoum North for provision of water to a small irrigation plot.

As part of the Western Savannah Development Project (WSDP), in collaboration with Overseas Development Agency (ODA) and the National Corporation for Rural Water Resources Development (NCRWRD), two Grundfos PV driven pumps were installed in a water yard (80-meters deep) in Southern Darfur. The pumps were severely undersized and were able to deliver just a small fraction of the daily water requirement. Another BP Solar/Grundfos pump was installed by the Overseas Development Agency for irrigating shelterbelts at northern agricultural project site at Kelli - north of Shendi.

The Swedish-Sudanese Friendship Association, a small NGO has also purchased four Grundfos solar pumps, and have been installed in villages near Bara in northern Kordofan. Two of these pumps were also evaluated during ERC/SREP testing campaign.

A 4kW-peak PV pump, donated by Japan, was also installed at the NCRWRD headquarterssouth of Khartoum. The system, designed to provide 100 cubic meters per day from a 100-meter head, was continuously over-pumping the well, because the actual total head was only 40 meters.

Two out of three PV pumps donated by the French Embassy through Total Energie Development were installed in Gezira and one in Karima. Both were out of service for long periods of time as a result of problems related to their control systems. 
As part of a five-year UNDP community-managed development program in Kordofan, installations of a number of PV pumping systems were also suggested.

A number of the above pumps were continuously monitored with hourly data including solar radiation, water output and pumping head. The effect of the pumping head on the performance of the PV system can be seen in Figure 5, where comparison is made for a similar system output under different pumping head (Foja and Sharasm El Karasha, near Bara). The 21-modules array was able to deliver approximately $80-\mathrm{m}^{2}$ of water at nearly $1 \mathrm{kw} / \mathrm{m}^{2}$ solar radiation and 24 $\mathrm{m}$ head. While the same unit delivered only $50-\mathrm{m}^{3}$ of water at 38 meter head and $1 \mathrm{~kW} / \mathrm{m}^{2}$ solar radiation.

The 21-modules unit at Gezira University delivered approximately $30-\mathrm{m}^{3}$ of water at 21 meter pumping head under solar radiation level of $6 \mathrm{kWh} / \mathrm{m}^{2} /$ day. Figures 5 and 6 show the variation of the system output and the efficiency of the array, subsystem and the overall efficiency of the pumping system with solar radiation respectively. The array efficiency was as expected, while the subsystem efficiency was relatively low. Generally the performance of the PV pumps were better than expected on some days, with average daily water delivery up to $10 \%$ above the manufacturers estimates. On cold shiny days the PV system performed better than predicted, while on hot days the performance was slightly lower; mainly due to temperature influence on the performance of the PV modules.

In general the test results of these four units indicate that Grundfos solar pumps are reliable for low to moderate heads (up to 40 meters). Application of Grundfos at deeper wells is not common, and the experience of PV systems near Nyala with pumping heads between 70 -100 meters was a typical example of PV pump limitation. However, now larger inverters (>1500 Watts) are readily available, and allows larger arrays to be assembled to drive water pumps under high pumping head (up to 120 meter), but at relatively low yield.

Table 2 summarises the results of the four PV systems included in the test.

\section{Fig. 5 Variation of the pumping rate with pumping head of the Grundfos Sp 4-8 PV water pump, [Hodgkin, 1991]}

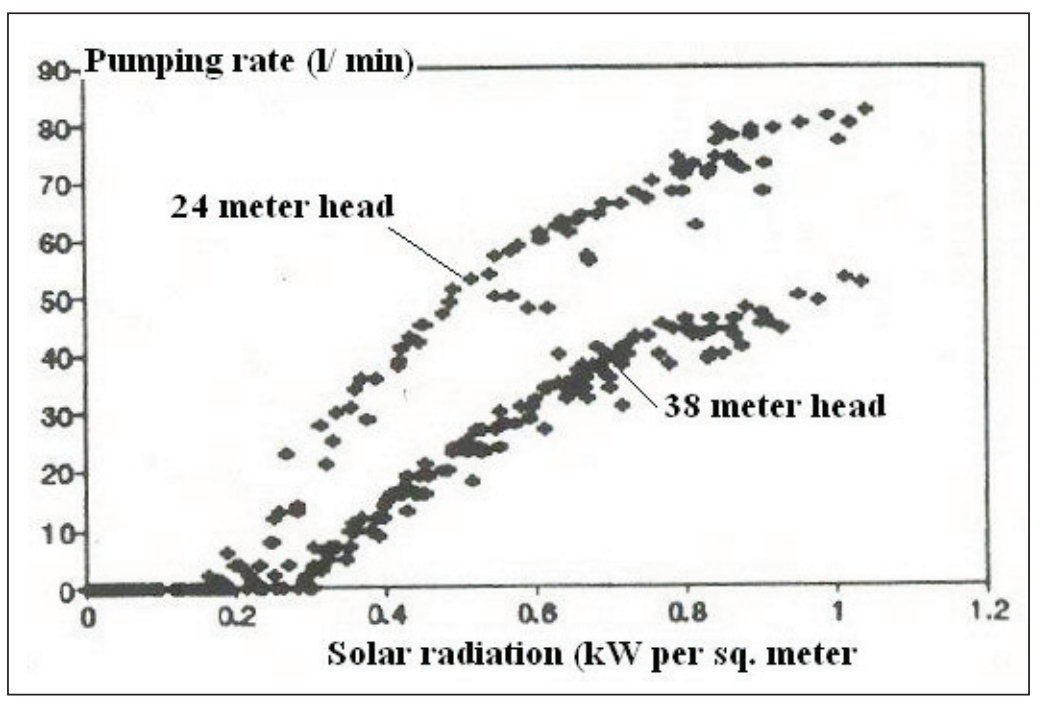


Fig. 6 Water output of the Grundfos Sp 4-8 PV water pumping system, [Hodgkin, 1991]

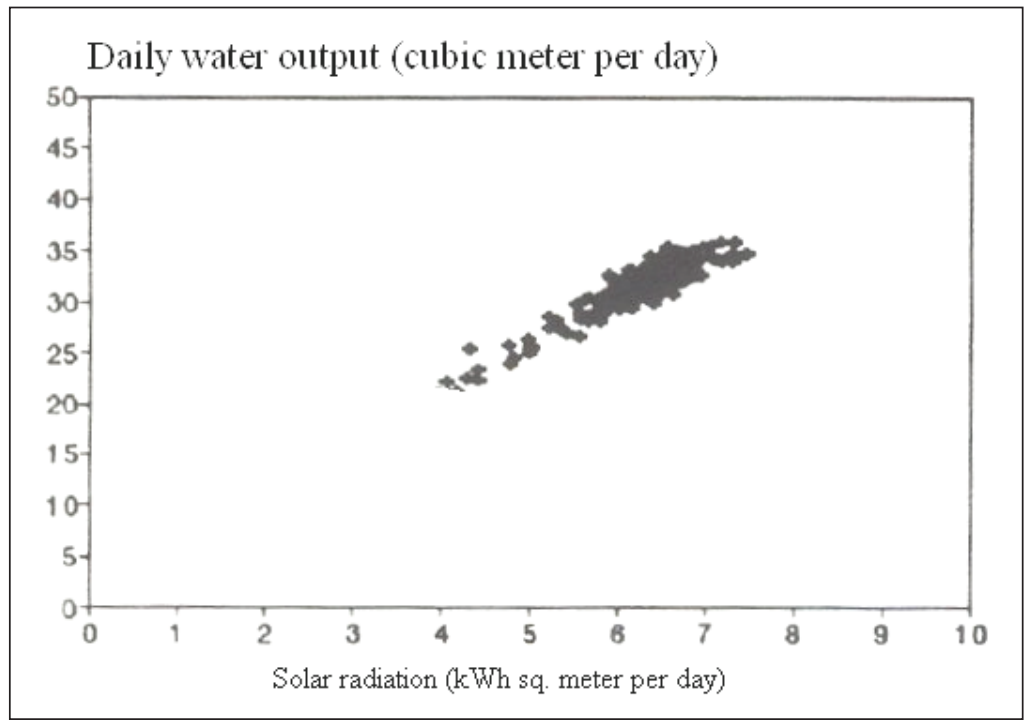

Fig. 7 Subsystems efficiency of the Grundfos PV water pumping system, [Hodgkin, 1991]

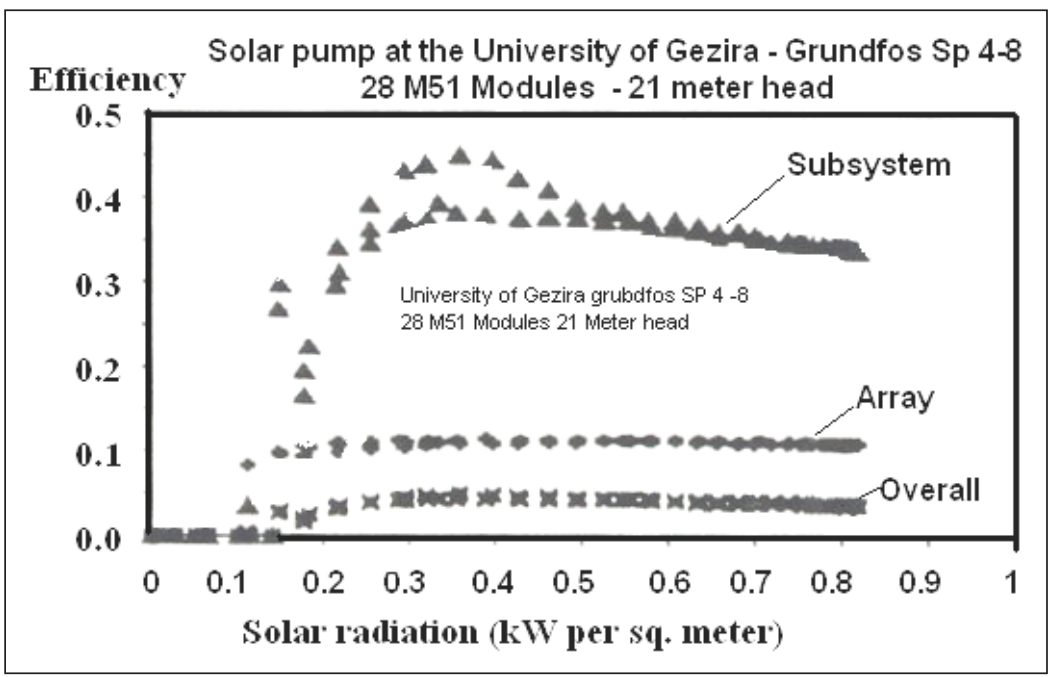

Table 2 Summary of PV solar pump field monitoring, [Hodgkin, 1991]

\begin{tabular}{|l|c|c|c|c|}
\hline \multicolumn{1}{|c|}{ PV Solar pump Site } & $\begin{array}{c}\text { Array size } \\
\text { (Wp) }\end{array}$ & $\begin{array}{c}\text { Pumping } \\
\text { head } \\
\text { (meters) }\end{array}$ & $\begin{array}{c}\text { Avg. Solar } \\
\text { rad. (kWh/ } \\
\left.\mathbf{m}^{2} / \mathbf{d a y}\right)\end{array}$ & $\begin{array}{c}\text { Avg. water } \\
\text { output } \\
\left(\mathbf{m}^{3} / \text { day) }\right.\end{array}$ \\
\hline University of Gezira (Wad Medani) & 1200 & 21 & 5.4 & 31.8 \\
\hline Hodeiba Research centre (Ad Damer) & 840 & 11 & 5.7 & 38.6 \\
\hline Foja/Shraim El Karasha (Bara) & 903 & $24 / 38$ & 5.6 & 21.0 \\
\hline Shambat (Khartoum North) & 360 & 7 & 6.2 & 35.7 \\
\hline
\end{tabular}




\subsubsection{PV Solar Refrigeration for vaccine storage}

Other area of solar electricity may include operation of refrigeration, especially for health centre in the remote areas. Storage of vaccines is a vital necessity in many developing countries especially for those which lie in the tropical zones. In most remote rural areas of the Sudan, health services are very poor. This is mainly due to the lack of storage of vaccines and drugs, due to the absence of energy supply to operate the storage systems. Most vaccines need to be stored in the temperature range between $-3 \mathrm{C}$ and $8{ }^{\circ} \mathrm{C}$, [El Tom, 1991]. However, in some areas in the Sudan, day temperature can reach and even exceed $40{ }^{\circ} \mathrm{C}$, so cooling of these materials is imperative. Nevertheless, without having a conventional energy source at one's disposal, the existence of mechanical refrigerators connected to photovoltaic panels could present a possible solution to this difficulty.

Energy Research Council has conducted field test of solar refrigeration in the early 1990s and this has proved to be successful under Sudan climate, [El Tom, 1991]. The study conducted for the UNDP for Rural solar Energy Development in Northern Kordofan, [Omer, 1993] has also shown that there is an immediate a huge potential of solar PV refrigeration in the area.

\section{Conclusions}

Currently biomass and fossil fuels (fire wood and charcoal) are the dominant energy sources for most of the Sudan rural population. S far as electricity is concerned, the hydropower is the major source of energy for most the mid and northern Sudan following completion Marawi dam. However, solar energy remains and will continue to be the most interesting and viable alternative to many other energy resources in the remote rural areas of Sudan. Given the foreseeable cost, logistics of operating and maintaining fossil fuel based power generating system, as well as the adverse environmental impact of using fossil fuel, efforts should be focused onto the introduction of solar energy technologies in the country, and lessons learned from the previous trails should be taken into account.

Most solar energy technologies evaluated for reliability by ERC and other organisations have proven to be very reliable; none of the technologies has experienced any serious technical drawback; rather, problems experienced were related to site selection and the quality of installation. This does not contradict the fact that some of the systems suppliers have overestimated their system performance, in part due to the lack of local climate conditions. Although, the cost of PV is coming down gradually, the major limiting factor to a wider application of solar systems in Sudan is the capital cost investment and lack of government incentives.

Implementation of solar technologies requires provision of technical support for development, engineering and production to local manufacturers and transfer of suitable designs to new areas. Stimulation of manufacturing industry through provision of proper training in the knowhow, operation and maintenance of solar technologies to end-users, is an important and urgent necessity for implementations of the solar technologies.

The Government and financial organisations need to provide financial support for investments in development, production and marketing as well as credit facilities for purchasers of solar technologies.

There is very limited emphasise on renewable energy technologies in general and solar energy in particular within the higher and education system, and therefore introduction of course related to renewable technologies within the higher education system is a necessity. 


\section{References}

EL Tom, O. M. M.; Omer, S. A.; Taha, A. Z. and Sayigh, A. A. M. (1991), Performance of a photovoltaic solar Refrigerator in tropical climate Conditions. Renewable Energy Vol. 1, No. 2, pp. 19-205, 1991.

Hodgkin, J, Omer SA, et al. (1991), Meeting rural water pumping needs in Sudan: An analysis of pumping system choice (diesel, wind or solar) - Report prepared for Energy Research Council, Khartoum- Sudan and U.S Agency for U. S. Agency for International Development, Khartoum, Sudan, and Sudan Energy Research Council under contract AID 650-0041-C-00-8014, 1991.

Omer, A. M. (1999), Compilation and evaluation of solar and wind energy resources in Sudan. Renewable Energy, Vol. 12 (1999), No. 1, pp. 3949.

Omer, Siddig and Taha, Azmi Z. (1993), Feasibility study of solar application in Sheikan Province, Kordofan State. A report prepared for Rural Solar Energy Development SUD/90/010, United Nation Development Program, Khartoum, 1993.

Solarbuzz (2009), Photovoltaic module retail prices (Dec 2001 - Jan 2009), available online at http://www.solarbuzz.com/, accessed on 3 December 2008.

Yasin M. Ibrahim (2008), Conceptual Design of Low-Energy Consumption Housing In Khartoum, SUDAN. A Dissertation submitted in partial fulfilment of the regulation for the Degree of Master of Science in Sustainable Building Technology at the University in Nottingham, 2008. 